\title{
Endometriosis: A Clinical Enigma
}

\author{
El Odokuma ${ }^{*}$, HO Abedi ${ }^{2}$, EA Onohwakpor ${ }^{2}$
}

\begin{abstract}
Endometriosis has been defined as the presence of endometrial tissue (gland and stroma) outside the inner lining of the endometrium. The lesion has been associated with debilitating and bizarre clinical features and in the absence of histopathologic assessment may result in severe consequences to the patient. Specifically, albeit rare, there is the possibility of malignant transformation. Therefore, this presentation on endometriosis as an unusual occurrence is of ardent import to health personnel, especially as regard to the requirements for in-depth intra/interdisciplinary consultation in general and the role of the pathologist, specifically in management of cases.

Materials and methods. This was the case of a 30-year-old self-employed nulliparous female who was referred from a secondary health facility due to abdominal swelling of eight-month duration. The swelling was progressive and associated with an unproductive cough, chest pain, weight loss and dysmenorrhoea. The patient was subjected to clinical examination, haematologic review, radiologic assessment and histopathologic investigations.

Results. The examination revealed dull percussion notes, reduced air entry into both right and left thoracic lung fields with bilateral crepitations in both lung fields. The abdomen was distended with massive ascitic fluid. The patient was stabilized and, consequently, an exploratory laparotomy demonstrated endometrial glands in the follicular phase with the associated stroma in the right ovaries. In sections of the omentum, there were endometrial glands and stroma, some of them were cystically dilated, filled with fluid and cellular debris in their lumen.

Contribution to knowledge. This study has established the existence of endometriosis in a woman in her reproductive years further substantiating the multiple distribution presentation, debilitating nature and the role of histopathologic input in management of this lesion.
\end{abstract}

\section{Keywords}

endometriosis; omentum; ovary; ascitis; malignancy

${ }^{1}$ Department of Anatomic Pathology, Delta State University Teaching Hospital, Oghara, Delta State, Nigeria

${ }^{2}$ Department of Obstetrics and Gynaecology, Delta State University Teaching Hospital, Oghara, Delta State, Nigeria

*Corresponding author: secretfiles1800@yahoo.com

\section{Problem statement and analysis of the recent research}

Endometriosis has been defined as the presence of endometrial tissue (gland and stroma) outside the inner lining of the endometrium [1,2]. Some authors have described the existence of this choristoma, especially in women in their reproductive years [3,4]. Though endometriosis is common in the ovaries and abdominal structures such as the omentum [4-7], it, however, has no specific site predilection [4].

The unpredictability of this lesion has resulted in some theories of its histogenesis. Some authors are of the view that endometriosis arises from reflux seeding of endometrial tissue from the endometrium through the fallopian tubes, vascular dissemination or inadvertent surgical transplant involving endometrial interventions [5-7], while others have opined that the lesion may arise from coelomic epithelial metaplasia. A few others have suggested the activation of embryonic cell rests [8-11].

Notwithstanding the possible aetiology, the lesion has been associated with debilitating and bizarre clinical features and in the absence of histopathologic assessment may result in severe consequences to the patient [12-15]. Specifically, albeit rare, there is the possibility of malignant transformation [16-21]. This presentation on endometriosis as an unusual occurrence is, therefore, of ardent import to health personnel especially as regard to the requirements for in-depth intra/interdisciplinary consultation in general and the role of the pathologist, specifically in management of cases.

\section{Case presentation}

This was the case of a 30-year-old self-employed nulliparous woman, who was referred from a secondary health facility due to abdominal swelling of eight-month duration. The swelling was progressive and associated with an unproductive cough, chest pain, weight loss and dysmenorrhoea.

The examination revealed dull percussion notes, reduced air entry into both right and left thoracic lung fields with bilateral crepitations in both lung fields. The abdomen was distended with massive ascitic fluid. Though the pouch of Douglas was filled with fluid, cervical excitation tenderness was negative on digital examination.

The working diagnosis was Meig's syndrome to rule out 


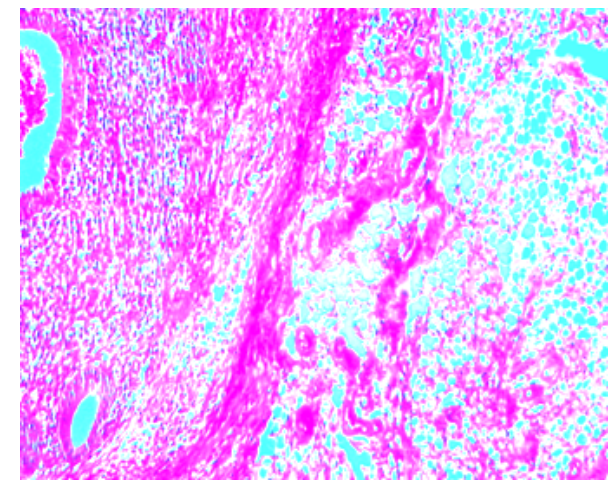

Figure 1. Omentum right with endometrial tissue, left; $\mathrm{H} \& \mathrm{E} ; \mathrm{x} 100$

abdominal tuberculosis with ovarian malignancy as differential. Ultrasonographic assessment revealed a non-gravid anteverted uterus measuring $8.0 \times 7.0 \times 4.0 \mathrm{~cm}$ with multiple uterine fibroid masses. Both ovaries were enlarged, $3.4 \times 3.7 \times 2.6 \mathrm{~cm}$ (right) and $4.9 \times 4.5 \times 5.2 \mathrm{~cm}$ (left), respectively. The patient had mild anaemia (haemoglobin - $10.9 \mathrm{~g} / \mathrm{dl}$ ).

The patient was subsequently stabilized, and an exploratory laparotomy demonstrated 6.7 litres of chocolate coloured ascitic fluid. There were extensive pelvic adnexal adhesions with an obvious sub-serous uterine mass. The working diagnosis was Meig's syndrome to rule out ovarian malignancy and abdominal tuberculosis. Ascitic fluid was obtained for cytology and left oophorectomy, myomectomy with omental biopsy were obtained via laparoscopic surgery.

Cytologic analysis revealed scant mesothelial cells on the background of abundant red blood cells. Ovarian biopsy showed several variably sized corporal lutea some of which were cystically dilated and filled with acellular material or blood cells. There were seen some endometrial glands in the follicular phase with the associated stroma. Some haemosiderinladen macrophages were observed in the immediate periphery of the endometrial tissue.

The myomectomy tissue showed fascicles of proliferating smooth muscle fibres disposed haphazardly and separated by a thin fibroconnective tissue stroma in which there were muscular arteries.

In sections of the omentum, there were seen adipocyte clusters separated by loose fibrovascular connective tissue stroma. In several foci, there were endometrial glands and stroma, some of them were cystically dilated, filled with fluid and cellular debris in their lumen. The glands were in the follicular phase.

Fig. 1, 2 present the sections of the omentum showing clusters of normal adipocytes distributed in the fibrovascular space. On the left, there are foci of endometrial stroma and glands.

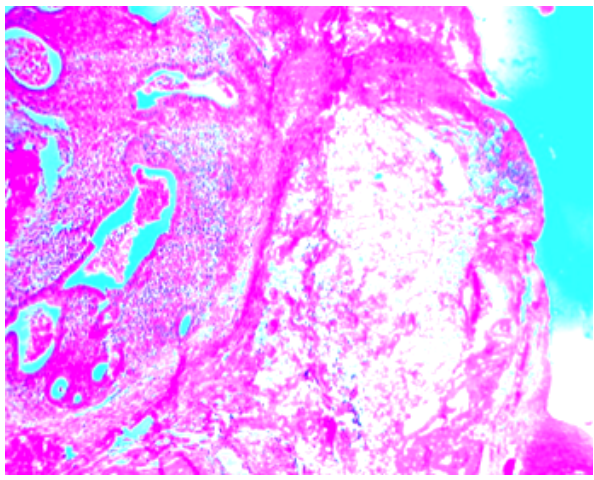

Figure 2. Omentum right with endometrial tissue, left; $\mathrm{H} \& \mathrm{E} ; \mathrm{x} 40$

\section{Conclusions}

Endometriosis has defined as the presence of endometrial tissue (usually gland and stroma) outside the inner lining of the uterus [3,4]. This gynaecologic disorder, which has been described as a common one among women in their reproductive years $[1,5]$ was found to be characterised by progressive abdominal swelling, unproductive cough, chest pain and dysmenorrhoea. These findings coincided with the results obtained by Dilemando Filho [22] who determined the accuracy of laparoscopy for assessing patients with endometriosis in 2008 and Sainz de la Cuesta et al, in 1996 [12].

The explanations for these observations are obvious. Despite the abdominal fullness ascitic fluid assessment showed chocolate coloured fluid with negative cervical excitation tenderness further suggesting a neoplastic process. Histopathologic review confirmed the presence of endometrial tissue in the omentum following laparotomy. Therefore, it is obvious that in spite of their unusual locations, endometriotic tissue respond to pituitary gonadotropins in the same manner as normal uterine tissue [23], i.e. the endometriotic tissue produces menstrual fluid wherever it is located. This was the reason for the observed abdominal fullness, straw coloured fluid, menstruating omental endometriotic tissue described in the results of the index study. This also explains the complaint of unproductive cough by the patient which resulted in homogenous opacity in both lung fields with the presence of unusual fluid collections in the lung parenchyma further compromising respiration stimulating cough reflexes, an adaptive response to counter the fluid collection.

Though X-ray revealed radiographic images that supported reduced air entry which was in keeping with the patient's presentation, anaemia, suggesting malignant neoplastic changes and ultrasonography that showed the enlarged ovaries, only histological assessment could adequately produce the confirmatory results of endometriosis. This additionally establishes histopathologic assessment as the gold standard in the verification of endometriosis [22].

The distribution of endometriotic tissue to the ovaries, the omentum and lungs (most likely) displayed in this study 
could be explained by the histogenesis of the lesion which, according to some authors, is due to vascular dissemination, coelomic metaplasia and embryonic cell rests and could unravel the above regional distribution $[5,6]$. Other authors have argued in support of reflux of endometrial tissue through the fallopian tubes and/or transplant of endometrial tissue during surgeries in the pelvis [7]. This may not likely expound the observations in this case, since the patient neither had a history of previous surgeries nor there was the lesion confined to the abdominal cavity.

This study has established the existence of endometriosis in a woman in her reproductive years and further substantiated the multiple distribution presentation of this lesion.

\section{Conflict of Interest}

The authors declare that there exists no conflict of interest in this study.

\section{Acknowledgement}

We wish to acknowledge the efforts of all the technical staff of the departments of Histopathology and Radiology who in many ways facilitated this study.

\section{References}

[1] Worley MJ, Welch WR, Berkowitz RS, Ng SW. Endometriosis-associated ovarian cancer: a review of pathogenesis. Int J Mol Sci. 2013;14(3):5367-5379. DOI: https://doi.org/10.3390/ijms14035367

[2] Giudice LC, Kao LC. Endometriosis. Lancet. 2004;364(9447):1789-1799. DOI: https://doi. org/10.1016/s0140-6736(04) 17403-5

[3] Olive DL, Schwartz LB. Endometriosis. N Engl J Med. 1993;328(24):1759-1769. DOI: https : / / doi .org/ $10.1056 /$ NEJM1 99306173282407

[4] Salati SA, Rather AA. Endometriosis: a rare cause of appendicitis. J Coll Physicians Surg Pak. 2011;(21)5:304305.

[5] Deger A, Yaylaf F, Bayhan Z. Endometriosis in the surgical scar tissue after caesarean section. Ann Clin Pathol. 2;(2):2022.

[6] Uysal A, Mun S, Taner CE. Endometrioma in abdominal scars: case reports of four cases and review of the literature. Arch Gynecol Obstet. 2012;286:805. DOI: https: //doi.org/10.1007/s00404-012-2320-8

[7] Mistrangelo M, Gilbo N, Cassoni P, Micalef S, Faletti R, Miglietta C et al. Surgical scar endometriosis. Surg Today. 2014;44(4):767-772. DOI: https : / / doi .org/ $10.1007 / \mathrm{s} 00595-012-0459-3$
[8] Pearce CL, Templeman C, Rossing MA, Lee A et al. Association between endometriosis and risk of histological subtypes of ovarian cancer: a pooled analysis of case-control studies. Lancet Oncol. 2012;13(4):385-394. DOI: https://doi .org/10. $1016 /$ S1470-2045(11) 70404-1

[9] Gazvani R, Templeton A. New considerations for the pathogenesis of endometriosis. Int. J Gynaecol Obstet. 2002;76(2):117-126. DOI: https://doi .org/10. $1016 / \mathrm{S} 0020-7292(01) 00577-\mathrm{X}$

[10] Halme J, Hammond MG, Hulka JF, Raj SG, Talbert LM. Retrograde menstruation in healthy women and in patients with endometriosis. Obstet Gynecol. 1984;64(2):151-154. [PMid:6234483]

[11] Sampson JA. Metastatic or embolic endometriosis, due to the menstrual dissemination of endometrial tissue into the venous circulation. Am J Pathol. 1927;3(2):93-110. [PMid:19969738 PMCid:PMC1931779]

[12] Sainz de la Cuesta R, Eichhorn JH, Rice LW, Fuller AF Jr, Nikrui N, Goff BA. Histologic transformation of benign endometriosis to early epithelial ovarian cancer. Gynecol Oncol. 1996;60(2):238-244. DOI: https : / / doi . org/10.1006/gyno.1996.0032 [PMid:8631545]

[13] Jiang QY, Wu RJ. Growth mechanisms of endometriotic cells in implanted places: a review. Gynecol Endocrinol. 2012;28(7):562-567. DOI: https://doi .org/10. $3109 / 09513590.2011 .650662$

[14] Vlahos NF, Economopoulos KP, Fotiou S. Endometriosis, in vitro fertilisation and the risk of gynaecological malignancies, including ovarian and breast cancer. Best Pract Res Clin Obstet Gynaecol. 2010;24:39-50. DOI: https://doi.org/10.1016/j.bpobgyn . 2009.08 .004

[15] Vlahos NF, Kalampokas T, Fotiou S. Endometriosis and ovarian cancer: a review. Gynecol Endocrinol. 2010;26(3):213-219. DOI: https://doi .org/10. $1080 / 09513590903184050$

[16] Kobayashi H, Sumimoto K, Moniwa N, Imai M, Takakura K, Kuromaki T, Morioka E, Arisawa K, Terao T. Risk of developing ovarian cancer among women with ovarian endometrioma: a cohort study in Shizuoka, Japan. Int J Gynecol Cancer. 2007;17(1):37-43. DOI: https : / / doi . org/10.1111/j.1525-1438.2006.00754.x

[17] Brinton LA, Gridley G, Persson I, Baron J, Bergqvist A. Cancer risk after a hospital discharge diagnosis of endometriosis. Am J Obstet Gynecol. 1997;176(3):572-579. DOI: https : / / doi .org/10. $1016 /$ s $0002-9378$ (97) 70550-7 
[18] Melin A, Sparén P, Persson I, Bergqvist A. Endometriosis and the risk of cancer with special emphasis on ovarian cancer. Hum Reprod. 2006;21(5):1237-1242. DOI: https://doi.org/10.1093/humrep/dei 462

[19] Vercellini P, Parazzini F, Bolis G, Carinelli S, Dindelli M, Vendola N, Luchini L, Crosignani PG. Endometriosis and ovarian cancer. Am J Obstet Gynecol. 1993;169:181-182. DOI: https://doi.org/ 10.1016/0002-9378(93) 90159-G

[20] Ogawa S, Kaku T, Amada S, Kobayashi H, Hirakawa T, Ariyoshi K, Kamura T, Nakano H. Ovarian endometriosis associated with ovarian carcinoma: a clinicopathological and immunohistochemical study. Gynecol Oncol. 200;77(2):298-304. DOI: https://doi.org/ $10.1006 /$ gyno.2000.5765

[21] Kumar S, Munkarah A, Arabi H, Bandyopadhyay S, Semaan A, Hayek K, Garg G, Morris R, Ali-Fehmi R. Prognostic analysis of ovarian cancer associated with endometriosis. Am J Obstet Gynecol. 2011;204(63):6167. DOI: https://doi.org/10.1016/j.ajog. 2010.08 .017

[22] Dilermando P, Laerte J, Vivian F. Accuracy of laparoscopy for assessing patients with endometriosis. Sao Paulo Med J. 2008;126(6):305308. DOI: https://doi.org/10.1590/ s1516-31802008000600002

[23] Khairy GA. Endometriosis of the appendix: a trap for the unwary. Saudi J Gastroenterol. 2005;11:45-47. DOI: https://doi.org/10.4103/1319-3767. 33337 [PMid:19861847]

Received: 13 Feb 2018

Revised: 25 Feb 2017

Accepted: 25 Feb 2017 